\section{Validity of maternal report on birth weight 11 years after delivery: the 1993 Pelotas Birth Cohort Study, Rio Grande do Sul State, Brazil}

\author{
Validade do relato materno de peso ao nascer \\ 11 anos após o parto: Coorte de Nascimentos \\ de 1993 em Pelotas, Rio Grande do Sul, Brasil
}

\author{
${ }^{1}$ Faculdade de Medicina, \\ Universidade Federal de \\ Pelotas, Pelotas, Brasil. \\ Correspondence \\ C. L. P. Araújo \\ Programa de Pós-graduação \\ em Epidemiologia, Faculdade \\ de Medicina, Universidade \\ Federal de Pelotas. \\ Av. Duque de Caxias 250, \\ 3o piso, Pelotas, RS \\ 96030-002, Brasil. \\ cora.araujo@terra.com.br
}

\begin{abstract}
Birth weight has short and long-term effects on health. Some studies have used retrospective data on birth weight, reported by the subject or by the parents. This paper compares data on birth weight measured by the research team in 1993 with birth weight reported by the mother in 2004-2005, using data from the 1993 Pelotas Birth Cohort Study, Rio Grande do Sul State, Brazil. We also evaluate the role of misclassification when exploring the effect of birth weight on a given outcome. Mean difference between the two variables was $20 \mathrm{~g}(S D=288.3)$. Agreement for detecting low birth weight was $95.2 \%$ in the sample as a whole (kappa =0.73), but was lower among low-schooling mothers. Mothers of children weighing less than 3,500g at birth tended to overestimate the child's birth weight. Inversely, mothers of heavier children tended to underestimate the values. One out of four mothers reported a difference of at least $200 \mathrm{~g}$ in birth weight as compared to that measured in 1993. Use of reported birth weight diluted the magnitude of the association with body mass index at 11 years in comparison with measured birth weight. Reported birth weight should be used with great caution, if at all.
\end{abstract}

Birth Weight; Prospective Studies; Cohort Studies
Cora L. P. Araújo 1

Carmem L. C. Dutra 1

Pedro C. Hallal 1

\section{Introduction}

The short and long-term effects of birth weight on health are well established. In the short term, low birth weight children are more likely to die in the first years of life and are also at increased risk of morbidity 1,2. In the long term, an inverse association between birth weight and various chronic diseases has been described 3,4,5,6. Therefore, utilization of birth weight as an exposure variable is frequent in the literature.

Birth weight is now routinely recorded at hospitals in most places, particularly in high-income countries. However, it was noted some years ago that several places still failed to record this information on a routine basis. Therefore, several studies have used retrospectively reported data on birth weight $7,8,9$.

In a previous publication, we showed that maternal information on birth weight 12 months after delivery was valid and reliable 10 in the sample as a whole, although mothers with low education provided less precise data on their child's birth weight. We hypothesized that the longer the recall period, the higher the likelihood of recall bias. In the present paper, we compare the information on birth weight measured by the research team in 1993 with that reported by the mothers in 2004-2005. We also evaluate the association between these two variables (measured and reported birth weight) and body mass index at 11 years. 


\section{Methods}

In 1993, mothers of all hospital-born children (> $99 \%$ of all deliveries) in the city of Pelotas $(\mathrm{N}=5,265)$ were invited to join a birth cohort study. Pelotas is located in the State of Rio Grande do Sul, in the southern region of Brazil. Data collection began on January 1 and ended December 31. Trained interviewers weighed the newborns using pediatric scales accurate to $10 \mathrm{~g}$. Interviews were conducted after delivery and included family, maternal, and pregnancy-related variables. Further details from the perinatal survey of the 1993 Pelotas Birth Cohort Study are available elsewhere 11.

In 2004-2005, we conducted a search of all cohort members for a follow-up visit. All schools and households in the city were visited to help locate children born in 1993. Data for the subjects identified ( $>80 \%$ of the original cohort members) using these two strategies were linked to the study database. For the remaining subjects, other strategies were used, including visits to addresses provided in 1993 and other visits to sub-samples of the cohort. Further details of the strategies used to ensure high follow-up rates in the 1993 Pelotas Birth Cohort Study are described elsewhere 12. Deaths between 1993 and 2005 were monitored.

During the 2004-2005 visit mothers were asked to provide their child's birth weight (open question). This information was collected only from the third month of the fieldwork onwards. Independent variables used in this paper were: child's gender, family income, maternal education, maternal age, maternal cohabitation, date of last menstrual period prior to the index gestation, and parity. The outcome variable, birth weight (measured in 1993 and reported in 20042005) was expressed both as a categorical (low birth weight: $<2,500 \mathrm{~g}-$ yes/no) and continuous variable.

Data analyses included calculations of sensitivity, specificity, predictive values, and kappa statistics for comparing birth weight categories using the two approaches (measured and recalled). In terms of the continuous variable, the Bland \& Altman 13 statistic was used to test agreement. This approach is more appropriate than simple correlation coefficients, because the former provides information on the magnitude and variability of the differences. T test, one-way ANOVA, and the Kruskal-Wallis test were used for continuous variables. Linear regression using body mass index (BMI) at 11 years as the outcome variable was also applied, using birth weight (measured and reported) as the independent variable. All analyses were performed using Stata 8.0 (Stata Corp., College Station, USA).
The Research Ethics Committee of the School of Medicine, Federal University in Pelotas, approved all phases of the study, and informed consent was obtained at each visit.

\section{Results}

Of the 5,249 cohort members, 141 are known to have died between 1993 and 2004-2005. The 3,426 subjects for whom information on birth weight was retrospectively collected at 11 years were similar to those for whom this information was not collected $(n=1,026)$ in terms of birth weight. Mean birth weight was 3,175g (SD = 523) among subjects included in our sample and $3,178 \mathrm{~g}$ $(\mathrm{SD}=519)$ among subjects not included in the sample. Subjects included in this analysis were also similar to those not included in terms of gender and socioeconomic status. Therefore, the decision to evaluate the validity of retrospective data on birth weight only after initiating the fieldwork is not likely to have biased our findings.

Hereinafter, analyses are presented only for the 3,426 subjects for whom retrospective information on birth weight was collected in 20042005. Table 1 presents the proportion of low birth weight according to 1993 measurements and 2004-2005 maternal recall. The agreement was $95.2 \%$ (kappa $=0.73$ ). The sensitivity and specificity of birth weight recall were $82.1 \%$ and $96.5 \%$, respectively. Positive and negative predictive values were $70.2 \%$ and $98.2 \%$, respectively. Prevalence of low birth weight was $9 \%$ according to 1993 measurements and $10.6 \%$ according to maternal recall in 2004-2005.

Table 2 stratifies the analyses by maternal schooling. Sensitivity was $75.2 \%$ in the group of mothers with low schooling, $85.1 \%$ for intermediate schooling, and $87 \%$ for high schooling. Specificity was $94.9,96.6$, and $98.1 \%$, respectively.

Mean birth weight according to 1993 measurements was $3,177 \mathrm{~g}(\mathrm{SD}=524)$, while mean birth weight based on maternal recall 11 years later was $3,197 \mathrm{~g}(\mathrm{SD}=574)$. Figure 1 presents the Bland \& Altman 13 plot comparing these two variables. The mean difference was $-20.0 \mathrm{~g}(\mathrm{SD}=$ 288.3). For 851 subjects, birth weight measured in 1993 was higher than reported in 2004-2005; for 1,277 individuals the values were identical; and for 2,324 subjects the value reported in 2004-2005 was higher.

Table 3 shows the mean difference between birth weight measured in 1993 and reported by the mother in 2004-2005. No differences were observed in the quality of the maternal report according to child's gender, family income, maternal age at delivery, or parity. Mothers of children 
Distribution of birth weight according to 1993 measurements and 2004-2005 maternal recall. Pelotas Birth Cohort Study, Rio Grande do Sul State, Brazil.

\begin{tabular}{lccc}
\hline Birth weight recall & \multicolumn{2}{c}{ Birth weight measurement } \\
& $<\mathbf{2 , 5 0 0 \mathrm { g }}$ & Total \\
\hline$<2,500 \mathrm{~g} 0 \mathbf{g}$ & 105 & 352 \\
$\geq 2,500 \mathrm{~g}$ & 247 & 2,927 & 2,981 \\
Total & 54 & 3,032 & 3,333 \\
\hline
\end{tabular}

Sensitivity: $82.1 \%$; specificity: $96.5 \%$; positive predictive value: $70.2 \%$; negative predictive value: $98.2 \%$; kappa: 0.73 .

Distribution of birth weight according to 1993 measurements and 2004-2005 maternal recall stratified by maternal schooling in 1993. Pelotas Birth Cohort Study, Rio Grande do Sul State, Brazil.

\begin{tabular}{|c|c|c|c|}
\hline & \multicolumn{2}{|c|}{ Birth weight measurement } & \multirow[t]{2}{*}{ Total } \\
\hline & $<2,500 \mathrm{~g}$ & $\geq 2,500 \mathrm{~g}$ & \\
\hline \multicolumn{4}{|c|}{ Low maternal schooling (0-4 years) } \\
\hline \multicolumn{4}{|c|}{ Birth weight recall } \\
\hline$<2,500 \mathrm{~g}$ & 79 & 42 & 121 \\
\hline$\geq 2,500 \mathrm{~g}$ & 26 & 785 & 811 \\
\hline Total & 105 & 827 & 932 \\
\hline \multicolumn{4}{|c|}{ Intermediate maternal schooling (5-8 years) } \\
\hline \multicolumn{4}{|c|}{ Birth weight recall } \\
\hline$<2,500 \mathrm{~g}$ & 120 & 48 & 168 \\
\hline$\geq 2,500 \mathrm{~g}$ & 21 & 1,357 & 1,378 \\
\hline Total & 141 & 1,405 & 1,546 \\
\hline \multicolumn{4}{|c|}{ High maternal schooling ( 9 years or more) } \\
\hline \multicolumn{4}{|c|}{ Birth weight recall } \\
\hline$<2,500 \mathrm{~g}$ & 47 & 15 & 62 \\
\hline$\geq 2,500 \mathrm{~g}$ & 7 & 783 & 790 \\
\hline Total & 54 & 798 & 852 \\
\hline
\end{tabular}

weighing less than 3,500g at birth tended to overestimate the child's birth weight 11 years later. Inversely, mothers of heavier children tended to underestimate these values.

One out of four mothers $(24.9 \%)$ reported a difference in birth weight of at least $200 \mathrm{~g}$ as compared to that measured in 1993. The proportion was $32.5 \%$ among mothers with $0-4$ years of schooling, $24 \%$ for $5-8$ years of schooling, $18 \%$ for 9 or more years of schooling ( $p<0.001)$. The proportion of disparity of at least $200 \mathrm{~g}$ was $31.5 \%$ for mothers who could not inform the date of their last menstrual period in 1993 and $24.1 \%$ for those who were able to provide this information $(\mathrm{p}=0.003)$.
Table 4 shows the association between birth weight (measured and reported) and BMI at 11 years. In both the sample as a whole and each target sub-group, the use of reported birth weight diluted the magnitude of the association with BMI.

\section{Discussion}

More than 20 years ago our group discussed the validity of maternal report of birth weight 12 months after delivery 10 . The article concluded that reported data were valid for the sample as a whole, but differed according to maternal 


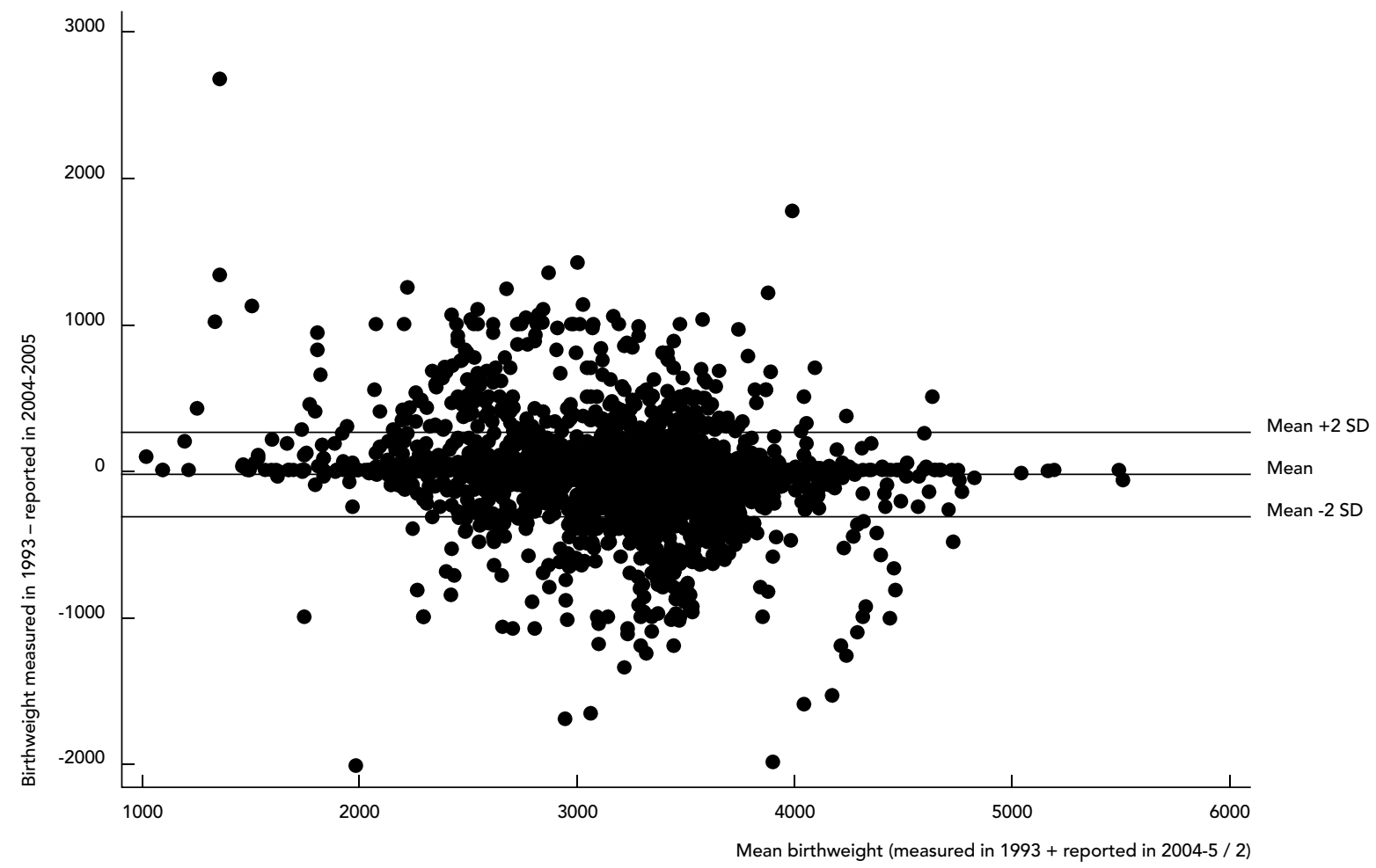

schooling. Now, using data from another birth cohort study in the same city, we have addressed the validity of the same information provided 11 years after delivery. This issue is particularly relevant given the long-term effects of birth weight on health. Life cycle studies preferentially use prospective data on birth weight, but retrospective data may be easier to obtain and allow more rapid analysis. Our data show that, although differences were not extreme for the sample as a whole, the use of reported birth weight may result in bias.

The first source of bias relates to differential misclassification according to key variables. Mothers with low schooling were less likely to provide valid data on their child's birth weight. Those with unknown gestational age in 1993 were more likely to provide imprecise data on their children's birth weight. In addition, regression to the mean was detected; i.e. mothers of small children tended to overestimate the child's birth weight, while mothers of heavier children tended to underestimate the child's birth weight.
Mothers living without a partner in 1993 provided less precise data on the child's birth weight 11 years after delivery.

The second source of bias concerns utilization of birth weight as an exposure variable. We used BMI at 11 years as an example of outcome variable, and our data show that measured birth weight provides a stronger association with the outcome than reported birth weight. Therefore, studies using retrospective reported data on birth weight as an exposure variable are likely to be affected by type 2 error.

Whether our findings apply to different populations is debatable. In high-income countries, most mothers have high levels of education, and therefore retrospective birth weight information may be more precise. For example, in the United Kingdom, a study including children 6 to 15 years of age 14 showed that $75 \%$ of mothers recalled birth weight within $50 \mathrm{~g}$ of that recorded in the hospital records; and no significant associations were found between difference in birth weight and parents' social class or child's age. Howev- 
Table 3

Difference between birth weight measured in 1993 and reported by mothers in 2004-2005 according to independent variables. Pelotas Birth Cohort Study, Rio Grande do Sul State, Brazil.

\begin{tabular}{|c|c|c|}
\hline Variable & $\begin{array}{l}\text { Difference in grams } \\
\text { Mean (SD) }\end{array}$ & $p$ * \\
\hline Gender & & 0.77 \\
\hline Male & $-21.5(294.1)$ & \\
\hline Female & $-18.5(282.6)$ & \\
\hline Family income in 1993 (times the minimum wage) & & 0.34 \\
\hline$\leq 1.0$ & $0.12(340.3)$ & \\
\hline $1.1-3.0$ & $-20.6(293.6)$ & \\
\hline $3.1-6.0$ & $-30.6(270.1)$ & \\
\hline $6.1-10.0$ & $-19.1(236.7)$ & \\
\hline$>10.0$ & $-32.7(216.1)$ & \\
\hline Maternal age in 1993 (years) & & 0.24 \\
\hline$<20$ & $-28.4(307.0)$ & \\
\hline $20-34$ & $-14.7(274.1)$ & \\
\hline$\geq 35$ & $-38.8(339.7)$ & \\
\hline Birth weight in 1993 (grams) & & $<0.001 * *$ \\
\hline$<1,500$ & $-203.5(696.2)$ & \\
\hline $1,500-2,499$ & $-50.6(319.9)$ & \\
\hline $2,500-3,499$ & $-38.4(286.9)$ & \\
\hline $3,500-4,499$ & $35.8(260.9)$ & \\
\hline$\geq 4,500$ & $63.9(365.4)$ & \\
\hline Parity & & 0.86 \\
\hline 0 & $-23.1(244.0)$ & \\
\hline 1 & $-11.0(287.4)$ & \\
\hline 2 & $-25.5(308.1)$ & \\
\hline 3 & $-20.2(298.6)$ & \\
\hline$\geq 4$ & $-23.4(373.9)$ & \\
\hline Maternal cohabitation in 1993 & & 0.04 \\
\hline Married/Living with partner & $-16.2(277.8)$ & \\
\hline Living without partner & $-47.3(353.9)$ & \\
\hline
\end{tabular}

* T-test for variables with two categories and one-way ANOVA for variables with three or more categories;

** Due to significant heterogeneity of variance, this $\mathrm{p}$ value was calculated using non-parametric statistics (Kruskal-Wallis test).

Table 4

Linear regression coefficients using body mass index at 11 years as the outcome variable and birth weight (measured and reported) as the exposure variable. Pelotas Birth Cohort Study, Rio Grande do Sul State, Brazil.

\begin{tabular}{lcc}
\hline $\begin{array}{l}\text { Family income } \\
\text { (times the minimum wage) }\end{array}$ & $\begin{array}{c}\text { Measured birth weight } \\
\text { Coefficients }(95 \% \mathrm{Cl})\end{array}$ & $\begin{array}{c}\text { Reported birth weight } \\
\text { Coefficients }(95 \% \mathrm{Cl})\end{array}$ \\
\hline$\leq 1.0$ & $1.11(0.69 ; 1.52)$ & $0.92(0.48 ; 1.36)$ \\
$1.1-3.0$ & $1.18(0.88 ; 1.47)$ & $0.87(0.57 ; 1.18)$ \\
$3.1-6.0$ & $0.96(0.52 ; 1.40)$ & $0.97(0.50 ; 1.45)$ \\
$6.1-10.0$ & $0.65(-0.11 ; 1.42)$ & $0.03(-0.83 ; 0.90)$ \\
$>10.0$ & $1.00(0.23 ; 1.76)$ & $0.70(-0.10 ; 1.71)$ \\
Total sample & $1.13(0.94 ; 1.33)$ & $0.91(0.70 ; 1.12)$ \\
\hline
\end{tabular}


er, in Northern Ireland 15, social class and birth weight were associated with quality of parental recall $12-15$ years after delivery.

One possible limitation to the current study is that information on birth weight was not collected retrospectively for all cohort members. In fact, 3,426 subjects were included, while the total cohort comprises 5,249 subjects. However, a comparison of birth weight between included and excluded members indicated no differences, thus minimizing the likelihood of selection bias. Another methodological consideration is that the predictive values presented here depend on the prevalence of birth weight in each population. In settings where birth weight is more frequent, these values will be higher if sensitivity and specificity are the same. This also applies to interpretation of the kappa results. Finally, some studies have opted to ask mothers categorically on birth weight (low, normal, high) when they cannot provide continuous data ${ }^{16}$. This could be a possible alternative for minimizing the number of missing values in studies using retrospective data.

In summary, our findings indicate that, in this population, utilization of retrospective data on birth weight may lead to misclassification, associated with maternal schooling, maternal cohabitation, and birth weight. Therefore, reported birth weight should be used with great caution, if at all. Studies on the early origins of adolescent and adult diseases 3,4,5,6 using retrospective birth weight as an exposure may have their effect measures diluted due to misclassification.

\section{Resumo}

O peso ao nascer exerce efeitos em curto e longo prazo sobre a saúde. Alguns estudos usam dados retrospectivos sobre o peso ao nascer, relatado pelo indivíduo ou pelos pais. Neste artigo nós comparamos o peso ao nascer medido em 1993 pela equipe de pesquisa com o relatado pela mãe em 2004-2005, usando-se dados da Coorte de Nascimentos de 1993 em Pelotas, Rio Grande do Sul, Brasil. Também avaliamos o papel do erro de classificação quando se explora a associação entre peso ao nascer e um determinado desfecho. A diferença média entre as duas variáveis foi de $20 \mathrm{~g}(\mathrm{DP}=288,3)$. O percentual de concordância para a detecção de baixo peso ao nascer foi de 95,2\% na amostra total (kappa = 0,73), mas foi menor entre as mães com baixa escola- ridade. As mães de crianças que nasceram com menos de $3.500 \mathrm{~g}$ tenderam a superestimar o peso ao nascer de seus filhos, enquanto as mães de crianças que nasceram com mais de $3.500 \mathrm{~g}$ tenderam a subestimar o peso ao nascer de seus filhos. Uma em cada quatro mães relatou um peso ao nascer mais de $200 \mathrm{~g}$ diferente do que foi medido em 1993. O uso do peso ao nascer relatado diluiu a associação com índice de massa corporal aos 11 anos de idade quando comparado ao peso ao nascer mensurado. O peso ao nascer relatado deve ser usado (se for usado) com muita cautela nessa população.

Peso ao Nascer; Estudos Prospectivos; Estudos de Coortes 


\section{Contributors}

C. L. P. Araújo coordinated the fieldwork in the 2004 2005 follow-up and headed the drafting of the article. C. L. C. Dutra reviewed the literature and revised the preliminary versions of the manuscript. P. C. Hallal coordinated the data analysis and revised the preliminary versions of the manuscript. All the authors approved the final version.

\section{References}

1. McCormick NC. The contribution of low birth weight to infant mortality and childhood morbidity. N Engl J Med 1985; 312:82-90.

2. Morris SS, Victora CG, Barros FC, Halpern R, Menezes AM, Cesar JA, et al. Length and ponderal index at birth: associations with mortality, hospitalizations, development and post-natal growth in Brazilian infants. Int J Epidemiol 1998; 27:242-7.

3. Barker DJP, Osmond C, Golding J, Kuh D, Wadsworth MEJ. Growth in utero, blood pressure in childhood and adult life, and mortality from cardiovascular disease. BMJ 1989; 298:564-7.

4. Barker DJP. Early growth and cardiovascular disease. Arch Dis Child 1999; 80:305-10.

5. Adair L, Dahly D. Developmental determinants of blood pressure in adults. Annu Rev Nutr 2005; 25:407-34.

6. Yajnik CS. Early life origins of insulin resistance and type 2 diabetes in India and other Asian countries. J Nutr 2004; 134:205-10.

7. Gulliford MC, Mahabir D, Rocke B, Chinn S, Rona R. Overweight, obesity and skinfold thicknesses of children of African or Indian descent in Trinidad and Tobago. Int J Epidemiol 2001; 30:989-98.

8. Whincup P, Cook D, Papacosta O, Walker M. Birth weight and blood pressure: cross-sectional and longitudinal relations in childhood. BMJ 1995; 311:773-6.

9. Walker BR, McConnachie A, Noon JP, Webb DJ, Watt GCM. Contribution of parental blood pressures to association between low birth weight and adult high blood pressure: a cross sectional study. BMJ 1998; 316:834-7.
10. Victora CG, Barros FC, Martines JC, Beria JU, Vaughan JP. Do mothers remember the birth weight of their children? Rev Saúde Pública 1985; 19:195-200.

11. Victora CG, Barros FC, Halpern R, Menezes AMB, Horta BL, Tomasi E, et al. Longitudinal study of the mother and child population in an urban region of southern Brazil, 1993: methodological aspects and preliminary results. Rev Saúde Pública 1996; 30: 34-45.

12. Victora CG, Araújo CL, Menezes AM, Hallal PC, Vieira MF, Neutzling MB, et al. Methodological aspects of the 1993 Pelotas (Brazil) Birth Cohort Study. Rev Saúde Pública 2006; 40:39-46.

13. Bland JM, Altman DG. Statistical methods for assessing agreement between two methods of clinical measurement. Lancet 1986; 8476:307-10.

14. O'Sullivan JJ, Pearce MS, Parker L. Parental recall of birth weight: how accurate is it? Arch Dis Child 2000; 82:202-3.

15. Walton KA, Murray LJ, Gallagher AM, Cran GW, Savage MJ, Boreham C. Parental recall of birthweight: a good proxy for recorded birthweight? Eur J Epidemiol 2000; 16:793-6.

16. Tilling K, Smith GD, Chambless L, Rose K, Stevens J, Lawlor $\mathrm{D}$, et al. The relation between birth weight and intima-media thickness in middleaged adults. Epidemiology 2004; 15:557-64.

Submitted on 05/May/2006

Final version resubmitted on $01 / \mathrm{Feb} / 2007$

Approved on 14/Feb/2007 